\title{
A Novel Mouse Model of Combined Hyperlipidemia Associated With Steatosis and Liver Injury by a Single-Dose Intragastric Administration of Schisandrin B/Cholesterol/Bile Salts Mixture
}

\author{
Si-Yuan Pan ${ }^{1, *}$, Zhan-Hong Jia ${ }^{1}$, Yi Zhang ${ }^{1}$, Qing $\mathrm{Yu}^{1}$, Xiao-Yan Wang ${ }^{1}$, Nan Sun ${ }^{1}$, Pei-Li Zhu ${ }^{1}$, \\ Zhi-Ling $\mathrm{Yu}^{2}$, and Kam-Ming $\mathrm{Ko}^{3}$ \\ ${ }^{1}$ Department of Pharmacology, School of Chinese Materia Medica, Beijing University of Chinese Medicine, \\ Beijing 100102, China \\ ${ }^{2}$ School of Chinese Medicine, Hong Kong Baptist University, Hong Kong, China \\ ${ }^{3}$ Division of Life Science, Hong Kong University of Science \& Technology, Hong Kong, China
}

Received May 16, 2013; Accepted July 21, 2013

\begin{abstract}
Hyperlipidemia is referred to as hypercholesterolemia, hypertriglyceridemia, or both in combined hyperlipidemia. Here, a novel mouse model of combined hyperlipidemia is described. Mice were orally given a single dose of a modeling agent (MA) made of a mixture of schisandrin B/ cholesterol/bile salts $(1 / 2 / 0.5 \mathrm{~g} / \mathrm{kg})$ suspended in olive oil. MA treatment increased serum triglycerides (TG) and total cholesterol (TC) (up to $422 \%$ and $100 \%$ at $12-96 \mathrm{~h}$ post-treatment, respectively) and hepatic TG and TC (up to $220 \%$ and $26 \%$, respectively) in a time- and dose-dependent manner, associated with elevation of high-density lipoprotein and low-density lipoprotein levels. Serum alanine/aspartate aminotransferase activities, indicators of liver cell damage, were also elevated (up to $198 \%$ ) at 48 and $72 \mathrm{~h}$ post-MA treatment. Fenofibrate blocks MA-induced hyperlipidemia, lipid accumulation in the liver, as well as liver injury. Oral administration of a mixture of schisandrin B, cholesterol, and bile salt could generate an interesting mouse model of combined hyperlipidemia associated with hepatic steatosis and steatohepatitis.
\end{abstract}

Keywords: combined hyerlipidemia, hepatic steatosis, hepatomegaly, schisandrin B, fenofibrate

\section{Introduction}

It is well known that hyperlipidemia (including hypercholesterolemia and hypertriglyceridemia, or their combination) is a prevalent health problem in modern societies. Due to their association with atherosclerosis, hyperlipidemia constitutes one of the major risk factors for vascular diseases such as coronary artery disease, a leading cause of death in developed countries, as well as hepatic steatosis $(1,2)$. Fatty liver-induced steatohepatitis, a specific pattern of injury within the spectrum of non-alcoholic fatty liver disease, can gradually lead to the development of fibrosis, cirrhosis, liver failure, and even hepatocellular carcinoma (3). In view of the adverse health consequences caused by hyperlipidemia, the

*Corresponding author. siyuan-pan@163.com Published online in J-STAGE on October 4, 2013 doi: $10.1254 /$ jphs.13087FP search for lipid-lowering drugs has been an area of intensive research. As such, the development of animal models of hyperlipidemia is instrumental to expedite the discovery of drugs to treat this problem. Experimental models of hyperlipidemia to date include high-fat dietor fructose-enriched diet-fed mice or rats $(4,5)$, apolipoprotein E-deficient (ApoE-/-) mice (6), LDL receptordeficient (Ldlr-/-) hypercholesterolaemic mice (7), glutamate-cysteine ligase modifier subunit gene-deficient [Gclm(-/-) mice (8), APOE*3Leiden.cholesteryl ester transfer protein (E3L.CETP)] (9), or ApoCIII transgenic mice or pigs (10) as well as combination of $L d l r-/-$ and high-fat diet-fed mice (7). Interestingly, ApoCIII transgenic animals showed significantly increased plasma triglyceride (TG) levels, but with minimal changes in plasma cholesterol (TC) concentrations (11).

Previous studies in our laboratory have shown that Schisandrin B (Sch B) treatment significantly increased serum and hepatic TG, but not TC, levels in mice, which 
led to the setting up of a mouse model of hypertriglyceridemia $(12,13)$. In the present study, a mouse model of combined hyperlipidemia (i.e., hypertriglyceridemia/ hypercholesterolemia) was created by a single intragastric administration of a mixture of Sch B, cholesterol (Ch), and a bile salt (Bs) suspended in olive oil. As hepatosteatosis is often associated with liver damage (14), we also examined the effects of the mouse model of dyslipidemia on liver damage.

\section{Materials and Methods}

\section{Chemicals and reagents}

Sch B was purified from the petroleum ether extract of dried fruits of Schisandra chinensis, as previously described (15). The purity of Sch B, as determined by high performance liquid chromatography analysis, was higher than 95\%. Fenofibrate (certificate No. 0405030) was bought from Beijing Yongkang Medical, Ltd. (Beijing, China). Ch (certificate No. 20110324) and Bs (certificate No. F20101214) were purchased from Beijing Chemical Reagent Co. (Beijing, China). Sodium carboxymethylcellulose (CMC, certificate No. 971230) was obtained from Beijing Xudong Chemical Plant (Beijing, China). Olivoila extra virgin olive oil was purchased from a local market. Fenofibrate was dissolved with $0.5 \% \mathrm{CMC}$ solution. Assay kits for measuring TC, TG, high density lipoprotein (HDL), and low density lipoprotein (LDL) levels, as well as alanine aminotransferase (ALT) and aspartate aminotransferase (AST) activities were bought from Zhongsheng Beikong Biotechnology and Science, Inc. (Beijing, China) or Beijing Leadman Biochemistry Co., Ltd. (Beijing, China).

\section{Animal care}

All animal experimental procedures were approved by the Institutional Animal Care and Use Committee of Beijing University of Chinese Medicine. Male ICR mice (Grade II, certificate No. SCXK(jing)2006-0009), weighing $18-20 \mathrm{~g}$, were purchased from Vital River Lab Animal Co., Ltd. (Beijing, China). They were maintained at $20^{\circ} \mathrm{C}-21{ }^{\circ} \mathrm{C}$, with a relative humidity of $50 \%-55 \%$ and allowed free access to water and food. Experiments were performed when the animals had attained a body weight of $24-26 \mathrm{~g}$.

\section{Preparation of the modeling agent}

The modeling agent (MA) tested in the present study was a mixture of Sch B, Ch, and Bs suspended in olive oil. A full dose of MA was made up of Sch B $(1 \mathrm{~g} / \mathrm{kg})$, $\mathrm{Ch}(2 \mathrm{~g} / \mathrm{kg})$, and Bs $(0.5 \mathrm{~g} / \mathrm{kg})$, with olive oil being administered at $20 \mathrm{~mL} / \mathrm{kg}$. A half dose of MA was exactly one half of a full dose of MA: Sch B, $0.5 \mathrm{~g} / \mathrm{kg}$;
Ch, $1 \mathrm{~g} / \mathrm{kg}$; and Bs, $0.25 \mathrm{~g} / \mathrm{kg}$, suspended in olive oil at $10 \mathrm{~mL} / \mathrm{kg}$. Both MAs were administered orally once for generating a mouse model of combined hypertriglyceridemia and hypercholesterolemia.

\section{Experimental design}

Design 1: In this study, mice received either Sch B $(1 \mathrm{~g} / \mathrm{kg})$ or $\mathrm{Ch} / \mathrm{Bs}(2 / 0.5 \mathrm{~g} / \mathrm{kg})$, with both being suspended in olive oil $(10 \mathrm{~mL} / \mathrm{kg})$. Control animals were orally administered vehicle $(10 \mathrm{~mL} / \mathrm{kg})$ only. Twenty-four hours following the treatment, animals were sacrificed. Blood, collected from the orbital vein under light ether anesthesia, and liver tissue samples were obtained and subjected to biochemical analysis.

Design 2: Mice were divided into two groups; 1) for the half-dose of MA group, animals were intragastrically treated with $\mathrm{Sch} \mathrm{B} / \mathrm{Ch} / \mathrm{Bs}(0.5 / 1 / 0.25 \mathrm{~g} / \mathrm{kg}$, suspended in olive oil, given at the dose of $10 \mathrm{~mL} / \mathrm{kg}$ ); 2) in the full-dose of MA group, animals received $\mathrm{Sch} \mathrm{B} / \mathrm{Ch} / \mathrm{Bs}$ $(1 / 2 / 0.5 \mathrm{~g} / \mathrm{kg}$, suspended in olive oil, given at the dose of $20 \mathrm{~mL} / \mathrm{kg}$ ). Control (i.e., non-Sch B/Ch/Bs-treated) animals were given vehicle only. Mice were sacrificed at $12,24,48,72,96$, and $120 \mathrm{~h}$ post-treatment.

Design 3: The aim of this experimental design was to explore the effect of hypolipidemic drug intervention in this model. Fenofibrate is a drug used to decrease blood TC and TG levels in the clinic. In this study, mice were intragastrically treated with fenofibrate $[0.1 \mathrm{~g} / \mathrm{kg}$, suspended in $0.5 \%\left(\mathrm{w} / \mathrm{v}\right.$, in $\left.\mathrm{H}_{2} \mathrm{O}\right) \mathrm{CMC}$ ) once daily for 3 days. The fenofibrate-untreated group received the vehicle $(10 \mathrm{~mL} / \mathrm{kg})$ orally for 3 days. On the fourth day of the experiment, mice were treated with fenofibrate dissolved in olive oil $(20 \mathrm{~mL} / \mathrm{kg})$ alone or a combination of fenofibrate and full-dose of MA. Fenofibrate-untreated animals were orally administered MA only. Control animals received vehicle only (olive oil, $20 \mathrm{~mL} / \mathrm{kg}$ ). Blood and liver samples were obtained at 24, 48, and 72 $\mathrm{h}$ after the last treatment.

\section{Measurement of lipid contents}

Serum samples, which were prepared by centrifuging the whole blood for $8 \mathrm{~min}$ at $2000 \times g$, were analyzed for lipid profiles using a Biocode Hycel Lisa 300 Hematology analyzer. Liver tissue samples were homogenized in 9 volumes of saline using two 10-s bursts of a tissue disintegrator at $13,500 \mathrm{rpm}$, and the homogenate was then centrifuged at $2000 \times g$ for $15 \mathrm{~min}$ to obtain the supernatants. The hepatic supernatants $(10$ or $40 \mu \mathrm{L})$ were used to determine the TG and TC levels, respectively, using assay kits according to the manufacturer's instructions. In essence, the enzyme-coupled reactions resulted in the formation of quinone imide, which can be measured spectrophotometrically (Spectrophotometer 
Unic UV-2000; Unico Instruments Co., Ltd., Shanhai, China) at $500 \mathrm{~nm}$. The concentration of TG or TC in the assay sample was estimated from the equation: (sample $\mathrm{OD} /$ standard OD) $\times$ standard concentration. Under the standard assay conditions described in the manufacturer's manual, the analytical range of the assay kit is $0-11.29$ $\mathrm{mmol} / \mathrm{L}$ for TG and $0-12.93 \mathrm{mmol} / \mathrm{L}$ for TC. Serum HDL and LDL levels, as well as ALT and AST activities were detected by an automatic Biochemistry Analyzer (Beckman Coulter Synchron CX4 PRO; Beckman, Brea, CA, USA).

\section{Measurement of hepatic index}

Liver weight was measured and hepatic index was estimated from the ratio of liver weight to body weight (liver weight / body weight $\times 100$ ) .

\section{Statistical analyses}

All group data are shown as the mean \pm S.E.M. Statistical comparisons were determined using either one-way ANOVA followed by Dunnett's multiple comparison test, Student's $t$-test, or post-hoc analysis using SPSS 16.0 for Windows. Differences were considered significant at $P<0.05$.

\section{Results}

Effects of Sch B, Ch/Bs, or their combination treatment on serum $T G$ and TC levels

Figure 1A shows that Sch B/olive oil $(1 \mathrm{~g} / 10 \mathrm{~mL} / \mathrm{kg})$ had no significant effect on TC, but serum TG levels were markedly increased (by 399\%) at $24 \mathrm{~h}$ post-dosing, when compared with the control; in contrast, $\mathrm{Ch} / \mathrm{Bs} /$ olive oil $(2 \mathrm{~g} / 0.5 \mathrm{~g} / 10 \mathrm{~mL} / \mathrm{kg})$ treatment increased TC (by $54 \%$ ) but decreased TG (by $41 \%$ ) under the same conditions. Changes in serum TG and TC levels produced by Sch B, Ch, and Bs combination treatment were timedependent. Sch B/Ch/Bs at the dose of $0.5 / 1 / 0.25 \mathrm{~g} / \mathrm{kg}$ (half-dose MA) increased the serum TG levels by $210 \%$, $157 \%, 36 \%, 19 \%$, and $13 \%$ at $12,24,48,72$, and $96 \mathrm{~h}$ post-treatment, respectively. After Sch B $(1 \mathrm{~g} / \mathrm{kg}), \mathrm{Ch}$ $(2 \mathrm{~g} / \mathrm{kg})$, and Bs $(0.5 \mathrm{~g} / \mathrm{kg})$ (full-dose MA) combination treatment, serum TG levels were increased by $84 \%$, $422 \%, 202 \%, 120 \%$, and $56 \%$ at $12,24,48,72$, and $96 \mathrm{~h}$, respectively (Fig. 1B). Serum TC concentrations in mice receiving half-/full-dose of MA were increased by $57 / 86 \%, 64 / 85 \%, 36 / 101 \%, 33 / 81 \%$, and $25 / 60 \%$ at $12,24,28,72$, and $96 \mathrm{~h}$, respectively, post-treatment (Fig. 1C).

\section{Effects of Sch B, Ch/Bs, or their combination treatment on hepatic TG and TC contents}

Treatment of mice with $\mathrm{Ch} / \mathrm{Bs}(2 / 0.5 \mathrm{~g} / \mathrm{kg})$ resulted
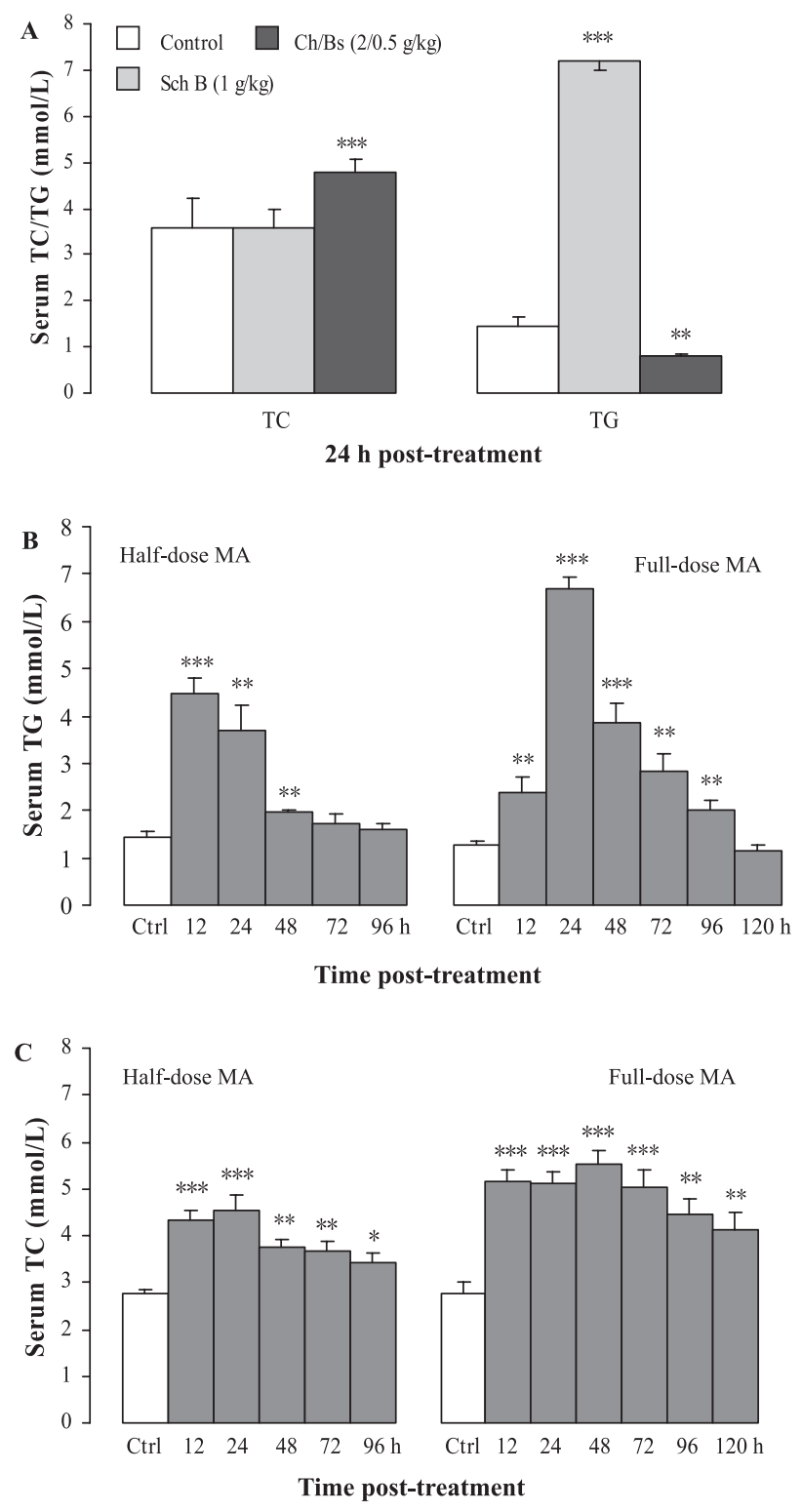

Fig. 1. Schisandrin B/cholesterol/bile salt-induced changes in serum triglyceride (TG) and total cholesterol (TC) levels in mice. Mice were orally administered Schisandrin B (Sch B) at $1 \mathrm{~g} / \mathrm{kg}$, cholesterol/bile salts $(\mathrm{Ch} / \mathrm{Bs}$ ) at $2 / 0.5 \mathrm{~g} / \mathrm{kg}(\mathrm{A})$, half-dose of MA (left panel in B and $\mathrm{C})$, or full-dose of MA (right panel in B and C). Control mice received vehicle (olive oil). Serum TG and TC levels were measured at 12, 24, $48,72,96$, and $120 \mathrm{~h}$ post-MA treatment or at $24 \mathrm{~h}$ post-vehicle treatment (control mice). However, all serum samples including control mice were collected on the same day. Our preliminary test showed that vehicle did not impact on the serum biomakers determined in the present study (data not shown) after 12 - 96-h treatment, compared with the water treatment. Therefore the control data at $12,48,72,96$, and $120 \mathrm{~h}$ after vehicle alone treatment was not presented. Values given are the mean \pm S.E.M., with $\mathrm{n}=10 .{ }^{*} P<0.05,{ }^{*} P<0.01$, $* * * P<0.001$ vs. control (Ctrl), using a one-way ANOVA followed by Dunnett's multiple comparisons test or Student's $t$-test. MA is the abbreviation for the modeling agent. Half-dose of MA treatment implies that $\mathrm{Sch} \mathrm{B} / \mathrm{Ch} / \mathrm{Bs}(0.5 / 1 / 0.25 \mathrm{~g} / \mathrm{kg}$, suspended in olive oil $10 \mathrm{~mL} / \mathrm{kg})$ is given to mice. Full-dose of MA treatment implies that $\mathrm{Sch} \mathrm{B} / \mathrm{Ch} / \mathrm{Bs}$ $(1 / 2 / 0.5 \mathrm{~g} / \mathrm{kg}$, suspended in olive oil $20 \mathrm{~mL} / \mathrm{kg})$ is given to mice. 
A
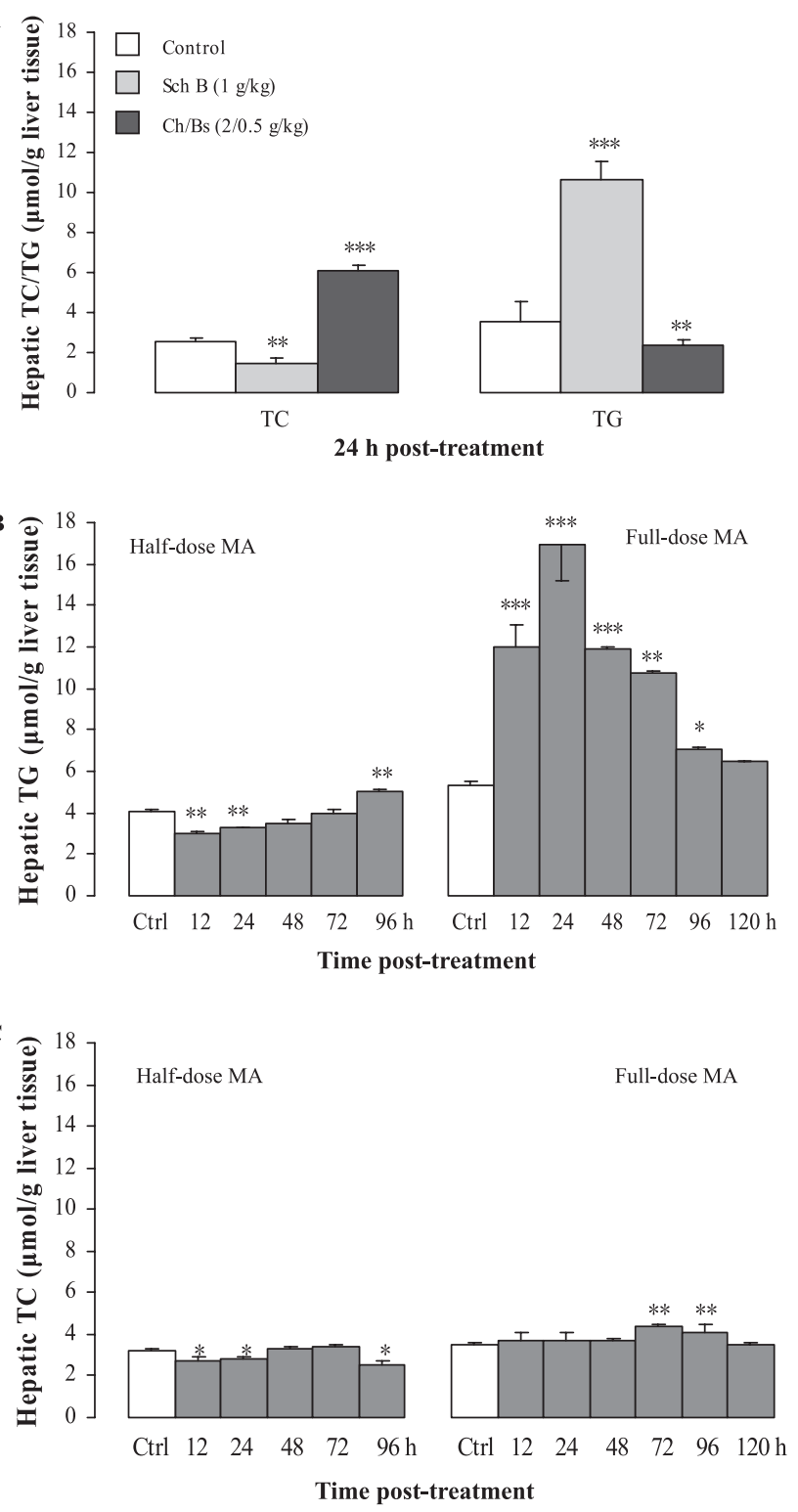

Fig. 2. Schisandrin $B /$ cholesterol/bile salt-induced changes in hepatic triglyceride (TG) and total cholesterol (TC) levels in mice. Experimental details are as described in Fig. 1. Hepatic TG and TC levels were measured at $12,24,48,72,96$, and $120 \mathrm{~h}$ post-treatment. Values given are the mean \pm S.E.M., with $\mathrm{n}=10 . * P<0.05, * * P<0.01$, $* * * P<0.001$ vs. control (Ctrl), using a one-way ANOVA followed by Dunnett's multiple comparisons test or Student's $t$-test.

in an increase (131\%) in hepatic TC but a reduction (37\%) in hepatic TG levels after $24 \mathrm{~h}$. In contrast, administration of Sch B $(1 \mathrm{~g} / \mathrm{kg})$ increased hepatic TG by $209 \%$, whereas hepatic TC levels decreased by $43 \%$ at the same time point (Fig. 2A). The effects of halfor full-dose MA treatment on hepatic TG and TC levels were investigated. The half dose of MA decreased hepatic TG by $25 \%$ and $20 \%$ at 12 and $24 \mathrm{~h}$ post- treatment, respectively, but increased hepatic TG by $24 \%$ at $96 \mathrm{~h}$. However, hepatic TG content was increased by $127 \%, 220 \%, 126 \%, 103 \%, 34 \%$, and $22 \%$ at 12,24 , $48,72,96$, and $120 \mathrm{~h}$, respectively, after a full dose of MA treatment (Fig. 2B). The half-dose MA treatment lowered hepatic TC (by $15 \%-20 \%$ ) at 12, 24, and $96 \mathrm{~h}$ post-treatment. Hepatic TC content was elevated (by $20 \%$ ) at 72 and $96 \mathrm{~h}$ post-MA treatment at full-dose (Fig. 2C).

\section{Effects of Sch B, Ch/Bs, or their combination treatment on hepatic function}

Treatment with $\mathrm{Ch} / \mathrm{Bs}$, but not $\mathrm{Sch} \mathrm{B}$, caused increases in activities of serum ALT (by 100\%) and AST (by $39 \%$ ), indicative of hepatic injury at $24 \mathrm{~h}$ post-treatment (Fig. 3A). However, half-dose of MA treatment produced no detectable effect on serum ALT and AST activities up to $72 \mathrm{~h}$ post-treatment. MA-treated mice at full-dose showed elevated activities of serum ALT (by 198\%) and AST (by 64\%) at $72 \mathrm{~h}$ post-treatment (Fig. 3: B and $\mathrm{C}$ ). Serum transaminase activities were slightly suppressed at 96 and $120 \mathrm{~h}$ after MA treatment at both doses.

Effects of Sch B, Ch/Bs, or their combination treatment on hepatic mass

Sch $\mathrm{B}$, but not $\mathrm{Ch} / \mathrm{Bs}$, treatment increased hepatic index (the ratio of liver weight to body weight) by $41 \%$ at $24 \mathrm{~h}$ post-treatment (Fig. 4A). MA markedly increased the hepatic index by $23 \%, 25 \%, 32 \%, 17 \%$, and $12 \%$ at $12,24,48,72$, and $96 \mathrm{~h}$, respectively, after half-dose of MA treatment. MA at full dose increased the hepatic index by $10 \%, 27 \%, 45 \%, 66 \%, 42 \%$, and $15 \%$ at 12 , $24,48,72,96$, and $120 \mathrm{~h}$ post-treatment, respectively (Fig. 4B).

\section{Effect offenofibrate pretreatment on serum lipid profiles in combined hyperlipidemic mice}

In addition to elevating serum TG and TC levels, Table 1 showed that MA treatment at full dose also increased serum HDL level (by $36 \%$ and $44 \%$, at 48 and $72 \mathrm{~h}$ post-treatment, respectively. LDL levels were also elevated by 58 and $97 \%$ at 24 and $48 \mathrm{~h}$, respectively, following the full-dose MA treatment. Fenofibrate pretreatment alone caused decreases in serum TG (by $54 \%$ and $45 \%$ at 24 and $48 \mathrm{~h}$ post-treatment, respectively) and TC (by $13 \%$ at $24 \mathrm{~h}$, respectively) levels. However, it increased serum TC by $35 \%$ at $48 \mathrm{~h}$ post-treatment. Combined treatment with fenofibrate and MA decreased serum TC, TG, and HDL levels by $27 \%, 52 \%$, and $22 \%$, respectively, at $72 \mathrm{~h}$ post-treatment, when compared with those of fenofibrate-untreated animals with MA. However, serum HDL levels in animals treated with both 

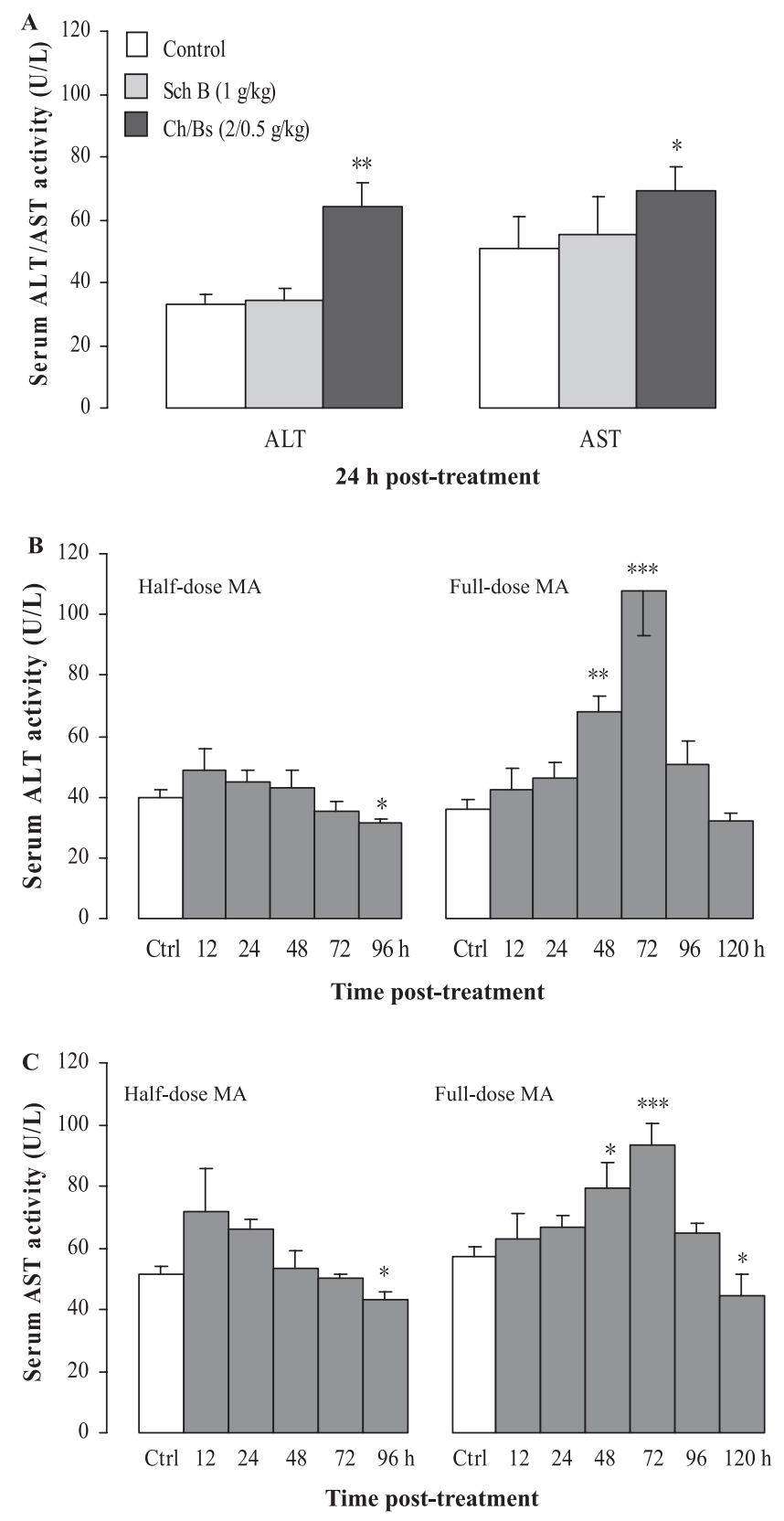

Fig. 3. Schisandrin $\mathrm{B} /$ cholesterol/bile salt-induced changes in hepatic function in mice. Experimental details are as described in Fig. 1. The serum alanine aminotransferase (ALT) and aspartate aminotransferase (AST) activities, biochemical indices of liver injury, were measured at $12,24,48,72,96$, and $120 \mathrm{~h}$ post-treatment. Values given are the mean \pm S.E.M., with $\mathrm{n}=10$. ${ }^{*} P<0.05$, $* * P<0.01$, $* * * P<0.001$ vs. control (Ctrl), using a one-way ANOVA followed by Dunnett's multiple comparisons test or Student's $t$-test.

MA and fenofibrate showed a further increase at $48 \mathrm{~h}$ after administration by $15 \%$ and $19 \%$ compared with MA and fenofibrate treatment alone, respectively. No detectable changes in these serum lipid parameters were apparent at 24 post-treatment (Table 1).
Effect of fenofibrate pretreatment on hepatic lipids contents in combined hyperlipidemic mice

MA induced the elevation of hepatic TC and TG levels. Hepatic TG levels were lowered by $46 \%, 37 \%$, and $25 \%$ at 24,48 , and $72 \mathrm{~h}$ after treatment with fenofibrate alone for 4 days, when compared with the corresponding control group, respectively. Combination of fenofibrate and full-dose MA treatment reduced TG levels by $32 \%, 56 \%$, and $46 \%$ at 24,48 , and $72 \mathrm{~h}$ after the last dosing, compared with the corresponding model group untreated with fenofibrate (Fig. 5A). Fenofibrate pretreatment effectively inhibited the MA-induced elevation of TC by $63 \%$ and $31 \%$ at 24 and $72 \mathrm{~h}$ after treatment, respectively (Fig. 5B). However, fenofibrate did not affect the hepatic TC content in mice receiving $\mathrm{MA}$ at $48 \mathrm{~h}$ post-treatment.

\section{Effects of fenofibrate pretreatment on hepatic index and} function in combined hyperlipidemic mice

Figure 6 shows that both fenofibrate and MA treatment at full dose individually markedly increased the hepatic index (by $17 \%-67 \%$ ), when compared with the control group. Combined treatment with fenofibrate and MA treatment further increased the hepatic index (by $76 \%-139 \%$ ) (Fig. 6A). Serum ALT activity was elevated (by $50 \%$ and $31 \%$ at 24 and $48 \mathrm{~h}$ post-dosing) in mice treated with fenofibrate. MA increased ALT activity by $34 \%$ and $103 \%$ at 48 and $72 \mathrm{~h}$ post-treatment, respectively. Combined treatment with fenofibrate and MA further increased ALT activity at $48 \mathrm{~h}$ post-treatment. However, fenofibrate pretreatment completely suppressed the MA-induced elevation in serum ALT activity at $72 \mathrm{~h}$ post-dosing (Fig. 6B).

\section{Discussion}

Over the last twenty years, several strains of genetically modified mice have been established to serve as animal models of lipid metabolism disorders. However, fat and/or cholesterol-enriched diets with variations in the lipid and carbohydrate components are still commonly used to induce hyperlipidemia in a variety of experimental animals including mouse, rat, golden hamster, guinea pig, rabbit, pigeon, and quail $(16-19)$. While an elevation of blood cholesterol level is always found in animal models of diet-induced hyperlipidemia, blood TG levels show inconsistent changes. Thus, elevations $(20,21)$, decreases $(17)$, or no changes $(22,23)$ of TG levels in the blood have been observed. Recently, Gómez-Pérez et al. reported that blood TG levels are increased in female mice and unchanged in male mice fed with the same high-fat diet (13\% protein, 33\% carbohydrate, and 54\% lipid) (24). 

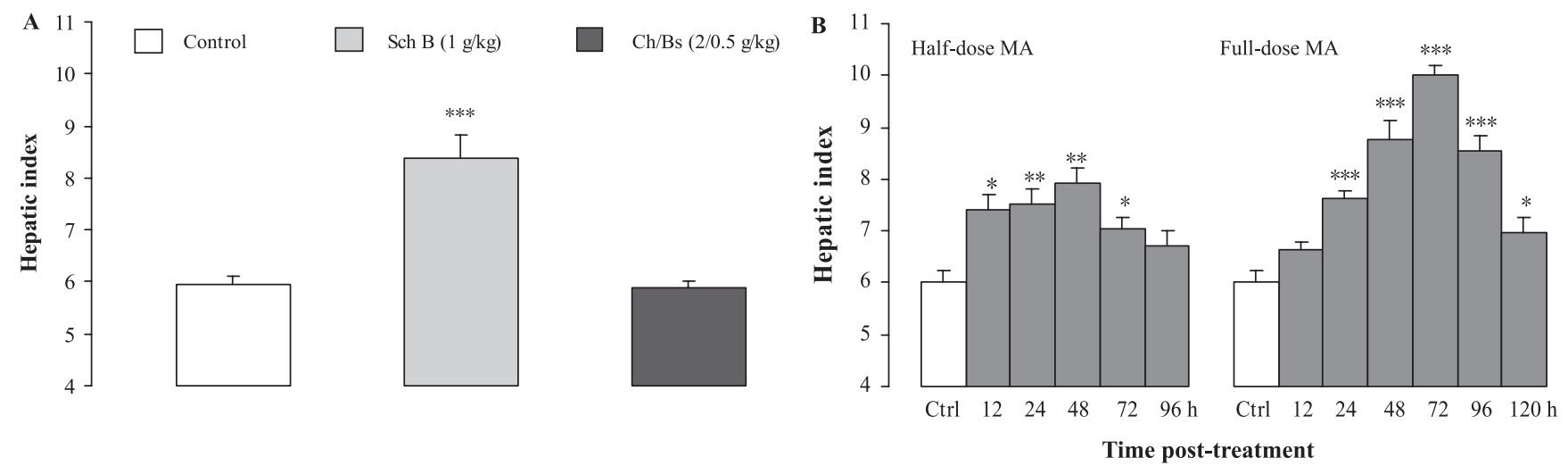

Fig. 4. Schisandrin B/cholesterol/bile salt-induced changes in hepatic index in mice. Experimental details are as described in Fig. 1. Hepatic index was measured at 12, 24, 48, 72, 96, and $120 \mathrm{~h}$ post-treatment. Values given are the mean \pm S.E.M., with $\mathrm{n}=10 . * P<0.05, * * P<0.01, * * * P<0.001$ vs. control (Ctrl), using a one-way ANOVA followed by Dunnett's multiple comparisons test or Student's $t$-test.

Table 1. Effects of fenofibrate pretreatment on serum lipid profiles in combined hyperlipidemic mice

\begin{tabular}{|c|c|c|c|c|}
\hline Groups & $\mathrm{TC}(\mathrm{mmol} / \mathrm{L})$ & $\mathrm{TG}(\mathrm{mmol} / \mathrm{L})$ & HDL (mmol/L) & LDL (mmol/L) \\
\hline \multicolumn{5}{|l|}{$24 \mathrm{~h}$ post treatment } \\
\hline Control & $3.52 \pm 0.13$ & $1.49 \pm 0.07$ & $3.64 \pm 0.12$ & $0.31 \pm 0.02$ \\
\hline Model & $4.49 \pm 0.28 * *$ & $5.57 \pm 0.44 * * *$ & $3.81 \pm 0.21$ & $0.49 \pm 0.07 *$ \\
\hline Fenofibrate & $3.05 \pm 0.15^{*}$ & $0.68 \pm 0.05^{* * *}$ & $3.29 \pm 0.15$ & $0.31 \pm 0.03$ \\
\hline Model/fenofibrate & $4.31 \pm 0.19^{* *, \#}$ & $5.19 \pm 0.27 * * *$,\#\# & $3.69 \pm 0.12$ & $0.46 \pm 0.06^{*, \#}$ \\
\hline \multicolumn{5}{|l|}{$48 \mathrm{~h}$ post treatment } \\
\hline Control & $3.11 \pm 0.15$ & $1.35 \pm 0.12$ & $3.30 \pm 0.16$ & $0.35 \pm 0.02$ \\
\hline Model & $5.41 \pm 0.28 * * *$ & $3.86 \pm 0.82 * * *$ & $4.49 \pm 0.25^{* * *}$ & $0.69 \pm 0.04 * * *$ \\
\hline Fenofibrate & $4.19 \pm 0.16^{* * *}$ & $0.74 \pm 0.11 * * *$ & $4.36 \pm 0.11 * * *$ & $0.53 \pm 0.03 * * *$ \\
\hline Model/fenofibrate & 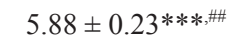 & $3.93 \pm 0.57 * * *$ & $5.17 \pm 0.13^{* * *, \# \#}$ & $0.64 \pm 0.03 * * *, \#$ \\
\hline \multicolumn{5}{|l|}{$72 \mathrm{~h}$ post treatment } \\
\hline Control & $3.42 \pm 0.13$ & $1.39 \pm 0.07$ & $3.54 \pm 0.12$ & $0.30 \pm 0.02$ \\
\hline Model & $5.31 \pm 0.33 * * *$ & $2.83 \pm 0.14 * * *$ & $5.10 \pm 0.31$ & $0.41 \pm 0.10^{*}$ \\
\hline Fenofibrate & $3.54 \pm 0.10$ & $1.44 \pm 0.17$ & $3.65 \pm 0.10$ & $0.30 \pm 0.04$ \\
\hline Model/fenofibrate & $3.87 \pm 0.12^{\dagger \dagger}$ & $1.26 \pm 0.14^{\dagger \dagger}$ & $3.99 \pm 0.12^{\dagger \dagger}$ & $0.32 \pm 0.05^{\dagger}$ \\
\hline
\end{tabular}

Mice were pretreated with fenofibrate $(0.1 \mathrm{~g} / \mathrm{kg}$ per day for 3 day, p.o.). On day 4 of the experiment, combined hyperlipidemic mice were intragastrically administered with a full dose of modeling agent, a mixture of schisandrin B/cholesterol/bile salt (1/2/0.5 g/kg), with and without fenofibrate co-treatment. Control mice received vehicle. Serum samples were obtained at 24, 48, and $72 \mathrm{~h}$ after the last treatment and were analyzed for total cholesterol (TC), triglyceride (TG), high density lipoprotein (HDL), and low density lipoprotein (LDL) levels. Values given are the mean \pm S.E.M., with $\mathrm{n}=10 . * P<0.05, * * P<0.01, * * * P<0.001$ vs. control group; ${ }^{\dagger} P<0.05,{ }^{\dagger \dagger} P<0.01$ vs. model group; ${ }^{\#} P<0.05,{ }^{\#} P<0.001$ vs. fenofibrate group. Differences were determined using a one-way ANOVA followed by Dunnett's post-hoc analysis.

Despite the fact that contemporary genetic models of hyperlipidemia are very sophisticated, they only focus on some genes that influence lipid metabolism on a specific target(s). For example, Ldlr-/- and ApoE-/- mice only emerge as a model of hypercholesterolaemia $(6,7)$; hypertriglyceridemia is observed in hypertriglyceridemic ApoCIII transgenic mice (10). However the pathogenesis of human hyperlipidemia is much more complex than that of genetic models except for familial hyperlipidemia. When compared with the existing genetic and diet-based models, our model has the advantages of simplicity and rapidity of development. The model reproduces manifestations of clinical hyperlipidemia such as hypertriglyceridemia, hypercholesterolemia, hyperlipoproteinemia, and fatty liver, as well as steatohepatitis.

Sch B is an active dibenzocyclooctadiene derivative 
A

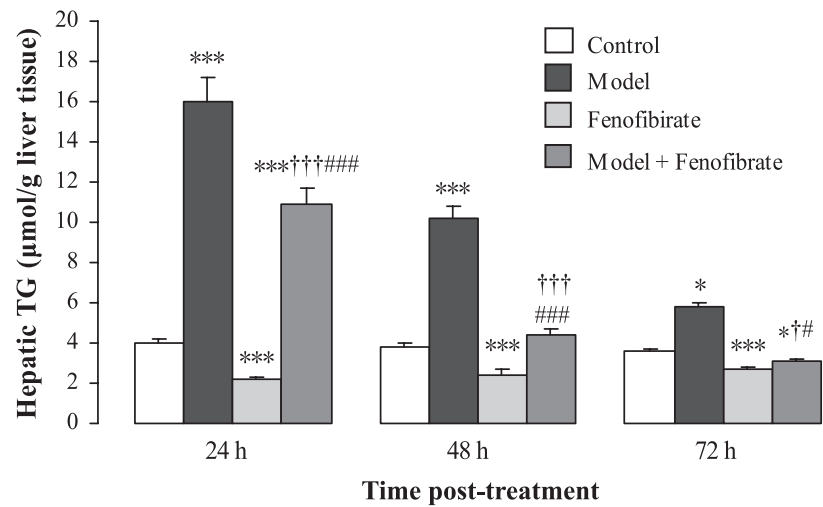

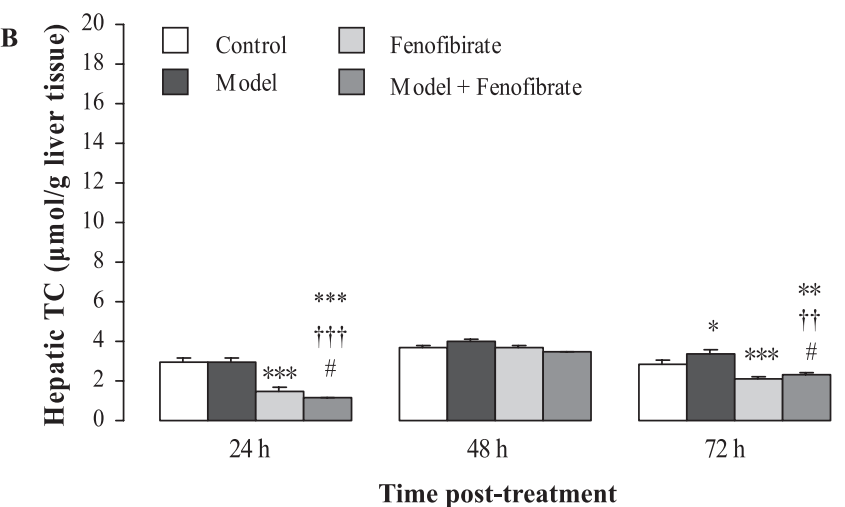

Fig. 5. Effects of fenofibrate pretreatment on hepatic triglyceride (TG) and total cholesterol (TC) contents in combined hyperlipidemic mice. Experimental details are as described in Table 1. Hepatic TG (A) and TC (B) contents were measured at 24, 48, and $72 \mathrm{~h}$ after the last treatment. Values given are the mean \pm S.E.M, with $\mathrm{n}=10$. $* P<0.05, * * P<0.01, * * * P<0.001$ vs. control (Ctrl); ${ }^{\dagger} P<0.05,{ }^{\dagger \dagger} P<0.01,{ }^{\dagger \dagger} P<0.001$ vs. model; ${ }^{\#} P<0.05,{ }^{\# \# \#} P<0.001$ vs. fenofibrate. Differences were determined using a one-way ANOVA followed by Dunnett's post-hoc analysis.
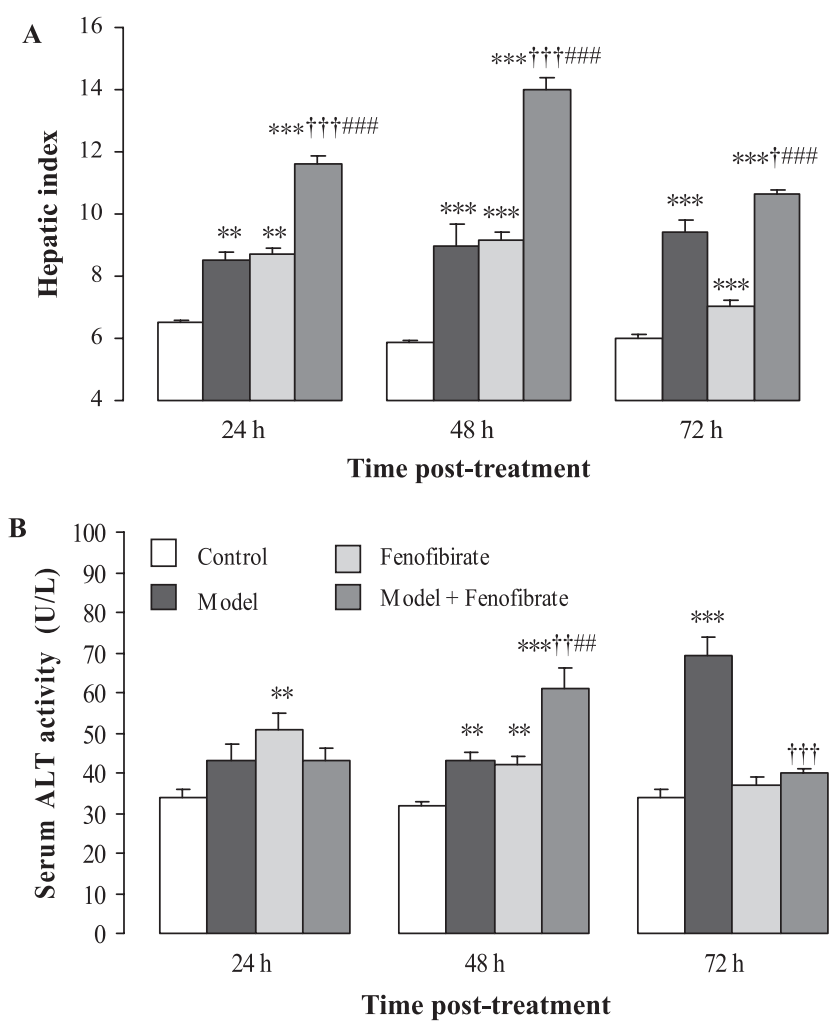

Fig. 6. Effects of fenofibrate pretreatment on hepatic index and function in combined hyperlipidemic mice. Experimental details are as described in Table 1. Hepatic index and serum alanine aminotransferases (ALT) were measured at 24, 48, and $72 \mathrm{~h}$ after the last treatment. Values given are the mean \pm S.E.M., with $\mathrm{n}=10$. ${ }^{* *} P<0.01$, ${ }^{* * *} P<0.001$ vs. control (Ctrl); ${ }^{\dagger} P<0.05,{ }^{\dagger \dagger} P<0.01,{ }^{\dagger \dagger} P<0.001$ vs. model; ${ }^{\#} P<0.01,{ }^{\#} P<0.001$ vs. fenofibrate. Differences were determined using a one-way ANOVA followed by Dunnett's posthoc analysis. isolated from the fruit of Schisandra chinensis, a deciduous woody vine native to forests of Northern China and the Russian Far East, which has been used as tonic and restorative adaptogen with notable liver protecting effects $(25,26)$. In the present study, Sch B increased TG levels in serum and liver tissue, resulting in hypertriglyceridemia and fatty liver. While high intake of cholesterol results in hypercholesterolemia, Bs (sodium salts of bile acids) can facilitate the intestinal absorption of lipids $(27,28)$, as well as induce liver injury by virtue of their pro-oxidant activity (29). Current investigations have shown that bile acids stimulate the regulation of early growth response factor-1 (Egr-1) via mitogen-activated protein kinase (MAPK) signaling in the liver during cholestasis, which causes liver injury (30). Although the exact mechanism of Sch B-induced hypertriglyceridemia is still unclear, the formulation of the current MA is very practical in that a mouse model of combined hyperlipidemia is able to serve the needs of research and development of lipid-lowering drugs.

MA used in the current study was found to markedly increase serum TG and TC levels in mice from 12 to $96 \mathrm{~h}$ post-treatment. The extent of MA-induced elevation of TC was not as large as that of TG in the liver. A representative microscopic picture of a hematoxylin and eosin-stained liver tissue section indicated that hepatic lipid deposits, which appeared as small vacuoles within the cytoplasm of liver cells, were found in model mice (data not shown). Hepatic TC and TG levels were reduced in the mice treated with half-dose MA. This may be attributed to the fact that $\mathrm{Ch} / \mathrm{Bs}$ and Sch B per se can produce a triglyceride- and cholesterol-lowering effect on the liver, respectively (13). However, the hepatic TC 
and TG were increased in the mice administered with high-doses Sch B, Ch, and Bs (full-dose MA). The observation that $\mathrm{Ch} / \mathrm{Bs}$ treatment increased hepatic $\mathrm{TC}$, but decreased the TG level, and that Sch B treatment increased hepatic TG, but decreased TC content, may be related to the possible reciprocal regulation of hepatic TC and TG levels in mice. The elevation of serum HDL level may be an event secondary to MA-induced hyperlipidemia and/or the increased serum LDL level. HDL particles remove TC from within artery atheroma and transport cholesterol back to the liver for excretion and/ or re-utilization (31). In contrast, LDL particles deposit cholesterol onto the vessel wall and lead to an increased risk of CAD (32).

Serum ALT and AST activities, which are biochemical parameters of liver cell injury, were increased at $24 \mathrm{~h}$ after the combined treatment with $\mathrm{Ch}$ and Bs. The $\mathrm{Ch} / \mathrm{Bs}$-induced liver injury is likely caused by the Bs component $(30,33)$. However, the combined treatment with a mixture of $\mathrm{Ch} / \mathrm{Bs}$ and $\mathrm{Sch} \mathrm{B}$ only slightly increased serum ALT and AST activities at $24 \mathrm{~h}$ posttreatment. This apparent hepatoprotective effect is likely related to the antioxidant activity and modulation of the $\mathrm{NF}-\kappa \mathrm{B}$ pathway of Sch B $(34-36)$. Recently, it was found that gomisin $\mathrm{N}$, the active component of Sch B, can inhibit the DNA damage checkpoint signaling by stereospecifically interacting with ataxia telangiectasia and Rad-3-related protein kinase (37). However, progressive increases in serum ALT and AST activities were observed in MA-treated mice from 48 to $72 \mathrm{~h}$ post-treatment. The result suggested that liver injury associated with steatosis/fatty liver (likely due to steatohepatitis) developed in a time-dependent manner in this mouse model of combined hyperlipidemia induced by MA.

To investigate potential applications of the mouse model, the effects of fenofibrate pretreatment on MAinduced changes were examined. Fenofibrate (a fibric acid agent) used alone or in combination with other agents has long been shown to have a beneficial effect in patients with hyperlipidemia. In essence, fenofibrate was found to reduce serum concentrations of LDL and $\mathrm{TG}$, with an associated increase in serum HDL. In the present study, fenofibrate treatment for 4 days was shown to reduce serum TG levels at 24 and $48 \mathrm{~h}$ after the last dosing. However, serum TC, HDL, and LDL levels were increased at $48 \mathrm{~h}$ following the drug withdrawal in non-hyperlipidemic mice. Fenofibrate treatment lowered hepatic TG contents (at 24, 48, and $72 \mathrm{~h}$ after the last dosing) and TC contents (at 24 and $72 \mathrm{~h}$, but not $48 \mathrm{~h}$, after the last dosing) in MA-induced hyperlipidemic mice. Fenofibrate-induced decreases in serum levels of TC and TG were found only at $72 \mathrm{~h}$ after the last dosing in MA-induced hyperlipidemic mice. The results indicated that fenofibrate is more effective in reducing hepatic levels than serum TC and TG levels in both normal and hyperlipidemic mice. The inability of fenofibrate to decrease hepatic TC content in hyperlipidemic mice at $48 \mathrm{~h}$ post-dosing may be related to liver damage caused by the combined treatment with fenofibrate and MA treatment.

Although current clinical data showed that fenofibrate reduced lymphocyte release of interleukin-2, interferon$\gamma$, and tumor necrosis factor- $\alpha$ (38), it can cause acute cholestatic hepatitis in patients given this drug at the dose of $300 \mathrm{mg}$ daily for $10-14$ days $(39-41)$. In the present study, fenofibrate treatment $(100 \mathrm{mg} / \mathrm{kg}$ per day for 4 day) was found to cause acute liver injury, which seemed to be reversed at $72 \mathrm{~h}$ after the final dosing. While the combined treatment with fenofibrate with MA further increased the extent of liver damage at $48 \mathrm{~h}$ post-treatment, fenofibrate pretreatment suppressed the MAinduced increase in serum ALT activity at $72 \mathrm{~h}$ after the last dosing. This hepatoprotective action of fenofibrate may, at least in part, be attributed to the fenofibrateinduced decline in hepatic lipids.

In conclusion, in the present study, a MA consisting of a mixture of Sch B, cholesterol, and Bs suspended in olive oil was investigated by examining its effect on plasma and hepatic lipid profiles as well as hepatic function. The results showed that this mouse model of combined hyperlipidemia, which simulates almost all aspects of hyperlipidemia in humans in a very short period of time (within 12-72 h), including hypertriglyceridemia and hypercholesterolemia as well as

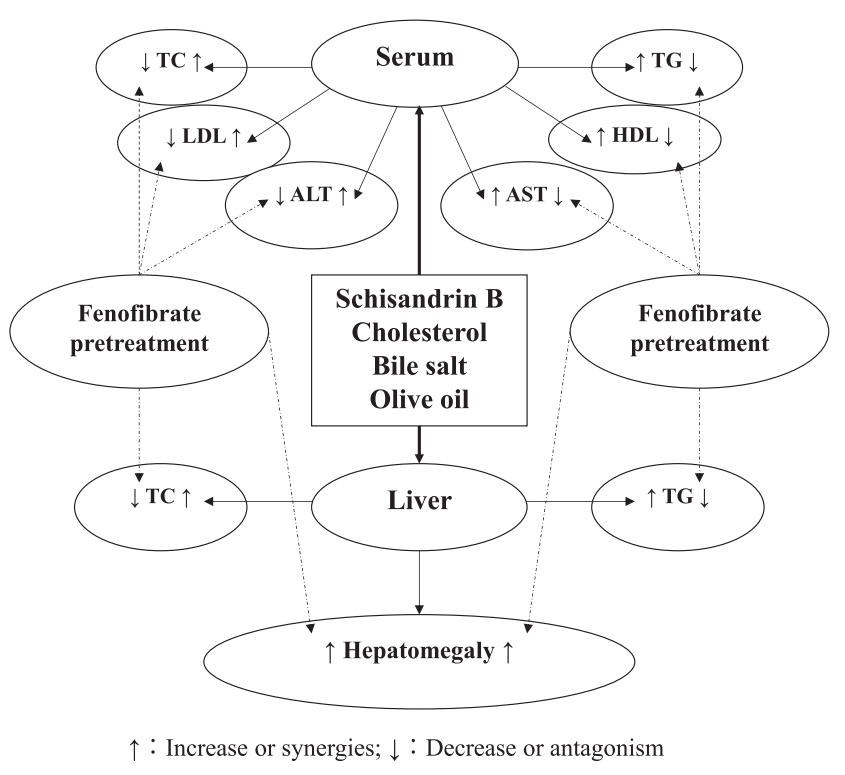

Fig. 7. A summary of the current research. 
significant elevations of the serum LDL and HDL level and ALT activity, was established by this mixture. The greatest extents of hyperlipidemia and hepatomegaly/ liver injury were observed at 24 and $72 \mathrm{~h}$, respectively, after MA administration. While hypercholesterolemia was maintained from 12 to $120 \mathrm{~h}$ post-treatment, fenofibrate pretreatment effectively suppressed the extents of hypertriglyceridemia, hypercholesterolemia, hepatic steatosis, and hepatic injury in MA-induced hyperlipidemic mice. In contrast, the combined treatment with fenofibrate and MA caused hepatomegaly in an apparently additive manner (summarized in Fig. 7). The mouse model of combined hyperlipidemia induced by $\mathrm{Sch} \mathrm{B} / \mathrm{Ch} / \mathrm{Bs}$ may prove useful for effectively assessing the effects of potential lipid-lowering drugs and related mechanisms underlying the regulation of lipid metabolism.

\section{Acknowledgments}

This paper was supported by the National Natural Science Foundation of China (Grant No. 31071989) and the Outstanding Teaching Team of Chinese Herbal Pharmacology in Beijing City (Grant No. 201006).

\section{References}

1 Yoon PW, Tong X, Schmidt SM, Matson-Koffman D. Clinical preventive services for patients at risk for cardiovascular disease, national ambulatory medical care survey, 2005-2006. Prev Chronic Dis. 2011;8:A43.

2 Rosamond W, Flegal K, Furie K, Go A, Greenlund K, Haase N, et al; American Heart Association Statistics Committee and Stroke Statistics Subcommittee. Heart disease and stroke statistics--2008 update: a report from the American Heart Association Statistics Committee and Stroke Statistics Subcommittee. Circulation. 2008;117:e25-e146.

3 Souza MR, Diniz Mde F, Medeiros-Filho JE, Araújo MS. Metabolic syndrome and risk factors for non-alcoholic fatty liver disease. Arq Gastroenterol. 2012;49:89-96.

4 Rogi T, Tomimori N, Ono Y, Kiso Y. The mechanism underlying the synergetic hypocholesterolemic effect of sesamin and $\alpha$ tocopherol in rats fed a high-cholesterol diet. J Pharmacol Sci. 2011;115:408-416.

5 Ackerman Z, Grozovski M, Oron-Herman M, Rosenthal T, Sela BA, Amir G. Effects of antihypertensive and triglyceride lowering agents on splenocyte apoptosis in rats with fatty liver. Basic Clin Pharmacol Toxicol. 2013;113:37-42.

6 Zadelaar S, Kleemann R, Verschuren L, de Vries-Van der Weij J, van der Hoorn J, Princen HM, et al. Mouse models for atherosclerosis and pharmaceutical modifiers. Arterioscler Thromb Vasc Biol. 2007;27:1706-1721.

7 Ma Y, Wang W, Zhang J, Lu Y, Wu W, Yan H, et al. Hyperlipidemia and atherosclerotic lesion development in ldlr-deficient mice on a long-term high-fat diet. PLoS One. 2012;7:e35835.

8 Chen Y, Curran CP, Nebert DW, Patel KV, Williams MT, Vorhees $\mathrm{CV}$. Effect of chronic glutathione deficiency on the behavioral phenotype of Gclm(-/-) knockout mice. Neurotoxicol Teratol. 2012;34:450-457.

9 van der Hoorn JW, Jukema JW, Havekes LM, Lundholm E, Camejo G, Rensen PC, et al. The dual PPARalpha/gamma agonist tesaglitazar blocks progression of pre-existing atherosclerosis in APOE*3Leiden.CETP transgenic mice. Br J Pharmacol. 2009;156:1067-1675.

10 Qu S, Perdomo G, Su D, D’Souza FM, Shachter NS, Dong HH. Effects of apoA-V on HDL and VLDL metabolism in APOC3 transgenic mice. J Lipid Res. 2007;48:1476-1487.

11 Wei J, Ouyang H, Wang Y, Pang D, Cong NX, Wang T, et al. Characterization of a hypertriglyceridemic transgenic miniature pig model expressing human apolipoprotein CIII. FEBS J. 2012;279:91-99.

12 Pan SY, Dong H, Han YF, Li WY, Zhao XY, Ko KM. A novel experimental model of acute hypertriglyceridemia induced by Schisandrin B. Eur J Pharmacol. 2006;537:200-204.

13 Pan SY, Dong H, Guo BF, Zhang Y, Yu ZL, Fong WF, et al. Effective kinetics of schisandrin $B$ on serum/hepatic triglyceride and total cholesterol levels in mice with and without the influence of fenofibrate. Naunyn Schmiedebergs Arch Pharmacol. 2011;383:585-591.

14 Depner CM, Torres-Gonzalez M, Tripathy S, Milne G, Jump DB. Menhaden oil decreases high-fat diet-induced markers of hepatic damage, steatosis, inflammation, and fibrosis in obese ldlr-/mice. J Nutr. 2012;142:1495-1503.

15 Ip SP, Poon MK, Wu SS, Che CT, Ng KH, Kong YC, et al. Effect of Schisandrin $\mathrm{B}$ on hepatic glutathione antioxidant system in mice: protection against carbon tetrachloride toxicity. Planta Med. 1995;61:398-401.

16 Pan SY, Dong H, Zhao XY, Xiang CJ, Fang HY, Fong WF, et al. Schisandrin B from Schisandra chinensis reduces hepatic lipid contents in hypercholesterolaemic mice. J Pharm Pharmacol. 2008;60:399-403.

17 Zhang Q, Wang G, A J, Ma B, Dua Y, Zhu L, et al. Metabonomic profiling of diet-induced hyperlipidaemia in a rat model. Biomarkers. 2010;15:205-216.

18 Yang R, Guo P, Song X, Liu F, Gao N. Hyperlipidemic guinea pig model: mechanisms of triglyceride metabolism disorder and comparison to rat. Biol Pharm Bull. 2011;34:1046-1051.

19 Liu XM, Wu FH. [Comparison of animal models of hyperlipidemia]. J Chin Intergr Med. 2004;2:132-134. (text in Chinese with English abstract)

20 Jung SA, Choi M, Kim S, Yu R, Park T. Cinchonine prevents high-fat-diet-induced obesity through downregulation of adipogenesis and adipose inflammation. PPAR Res. 2012;2012:541204.

21 Liu D, He Z, Wu L, Fang Y. Effects of induction/inhibition of endogenous heme oxygenase-1 on lipid metabolism, endothelial function, and atherosclerosis in rabbits on a high fat diet. J Pharmacol Sci. 2012;118:14-24.

22 Lin ZJ, Zhang B, Liu XQ, Yang HL. Abdominal fat accumulation with hyperuricemia and hypercholesterolemia quail model induced by high fat diet. Chin Med Sci J. 2009;24:191-194.

23 Wang X, Hasegawa J, Kitamura Y, Wang Z, Matsuda A, Shinoda W, et al. Effects of hesperidin on the progression of hypercholesterolemia and fatty liver induced by high-cholesterol diet in rats. J Pharmacol Sci. 2011;117:129-138.

24 Gómez-Pérez Y, Capllonch-Amer G, Gianotti M, Lladó I, Proenza AM. Gómez-Pérez Y, et al. Long-term high-fat-diet feeding induces skeletal muscle mitochondrial biogenesis in 
rats in a sex-dependent and muscle-type specific manner. Nutr Metab (Lond). 2012;9:15.

25 Panossian A, Wikman GP. Pharmacology of Schisandra chinensis Bail.: an overview of Russian research and uses in medicine. J Ethnopharmacol. 2008;18:183-212.

26 Kim KJ, Yoon KY, Hong HD, Lee BY. Schisandra chinensis prevents hepatic lipid peroxidation and oxidative stress in rats subjected to heat environmental stress. Phytother Res. 2012;26: $1674-1680$.

27 Iqbal J, Hussain MM. Intestinal lipid absorption. Am J Physiol Endocrinol Metab. 2009;296:E1183-E1194.

28 Calkin AC, Tontonoz P. Transcriptional integration of metabolism by the nuclear sterol-activated receptors LXR and FXR. Nat Rev Mol Cell Biol. 2012;13:213-224.

29 Joseph B, Kapoor S, Schilsky ML, Gupta S. Bile salt-induced pro-oxidant liver damage promotes transplanted cell proliferation for correcting Wilson disease in the Long-Evans Cinnamon rat model. Hepatology. 2009;49:1616-1624.

30 Allen K, Kim ND, Moon JO, Copple BL. Upregulation of early growth response factor- 1 by bile acids requires mitogen-activated protein kinase signaling. Toxicol Appl Pharmacol. 2010;243: 63-67.

31 Gao X, Yuan S, Jayaraman S, Gursky O. Role of apolipoprotein A-II in the structure and remodeling of human high-density lipoprotein: protein conformational ensemble on various HDL. Biochemistry. 2012;51:4633-4641.

32 Kim JH, Jeong MH, Hong YJ, Lee KH, Kim IS, Choi YH, et al. Low density lipoprotein-cholesterol/high density lipoproteincholesterol ratio predicts plaque vulnerability in patients with stable angina. Korean Circ J. 2012;42:246-251.

33 Watanabe S, Tsuneyama K. Cattle bile but not bear bile or pig bile induces lipid profile changes and fatty liver injury in mice: mediation by cholic acid. J Toxicol Sci. 2012;37:105-121.

34 Leong PK, Chiu PY, Ko KM. Prooxidant-induced glutathione antioxidant response in vitro and in vivo: a comparative study between schisandrin B and curcumin. Biol Pharm Bull. 2012; 35:464-472.

35 Lam PY, Leong PK, Chen N, Ko KM. Schisandrin B enhances the glutathione redox cycling and protects against oxidant injury in different types of cultured cells. Biofactors. 2011;37:439446.

36 Giridharan VV, Thandavarayan RA, Bhilwade HN, Ko KM, Watanabe K, Konishi T. Schisandrin B, attenuates cisplatininduced oxidative stress, genotoxicity and neurotoxicity through modulating NF- $\kappa$ B pathway in mice. Free Radic Res. 2012;46: $50-60$.

37 Tatewaki N, Nishida H, Yoshida M, Ando H, Kondo S, Sakamaki $\mathrm{T}$, et al. Differential effect of Schisandrin B stereoisomers on ATR-mediated DNA damage checkpoint signaling. J Pharmacol Sci. 2013;122:138-148.

38 Krysiak R, Gdula-Dymek A, Okopien B. The effect of fenofibrate on lymphocyte release of proinflammatory cytokines and systemic inflammation in simvastatin-treated patients with atherosclerosis and early glucose metabolism disturbances. Basic Clin Pharmacol Toxicol. 2013;112:198-202.

39 Maroy B. [Acute cholestatic hepatitis probably due to fenofibrate]. Therapie. 2010;65:147-148. (text in French)

40 Hajdu D, Aiglová K, Vinklerová I, Urbánek K. Acute cholestatic hepatitis induced by fenofibrate. J Clin Pharm Ther. 2009;34: 599-602.

41 Ho CY, Kuo TH, Chen TS, Tsay SH, Chang FY, Lee SD. Fenofibrate-induced acute cholestatic hepatitis. J Chin Med Assoc. 2004;67:245-247. 